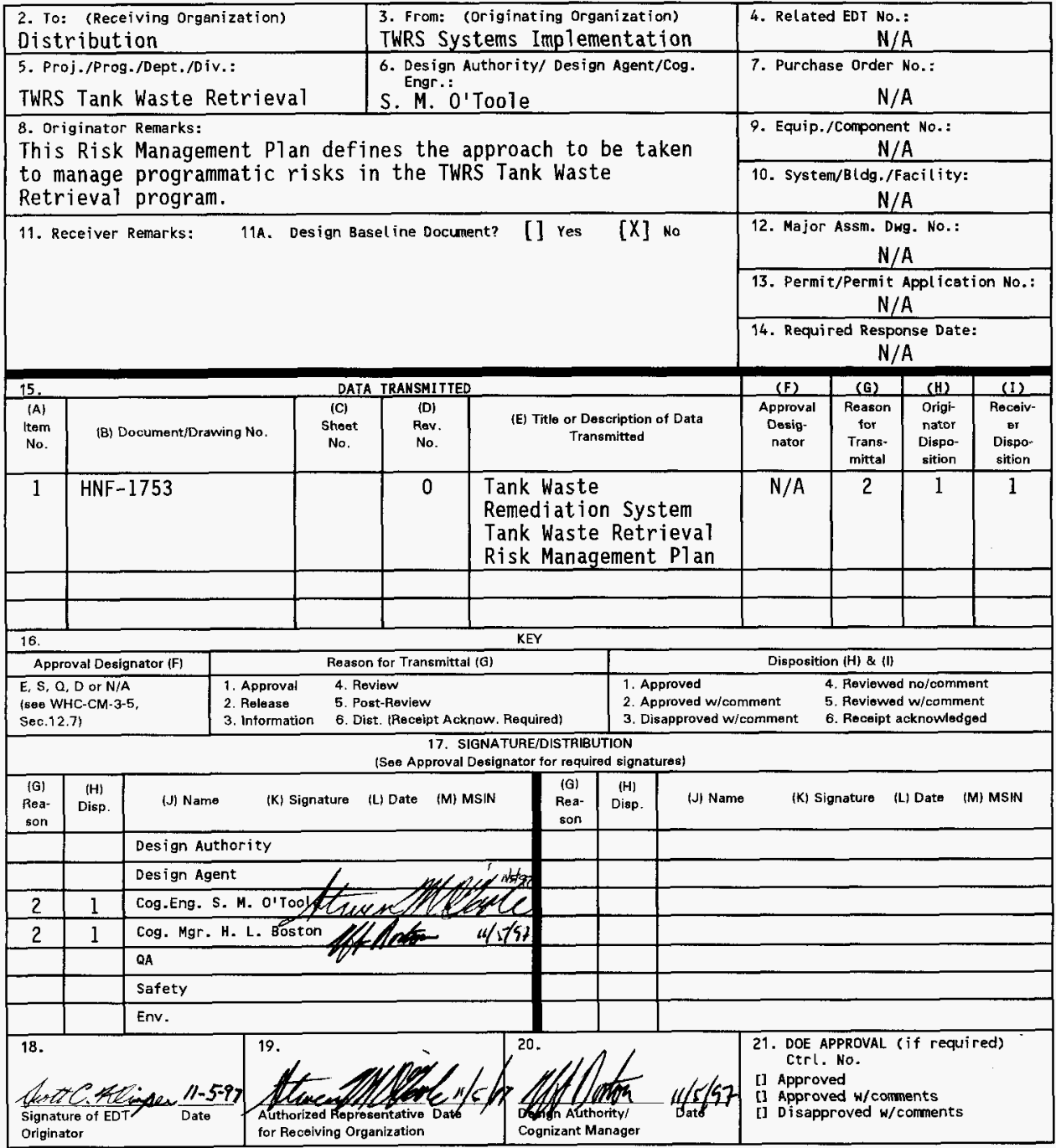

BD-7400-172-2(05/96) GEF097 


\section{Tank Waste Remediation System Tank Waste Retrieval Risk Management Plan}

\section{S.C. Kl imper}

Lockheed Martin Hanford Company, Richland, WA 99352

U.S. Department of Energy Contract DE-AC06-96RL13200

EDT/ECN: 622830

Org Code: 74210

B\&R Code: EW3130010
UC: 2030

Charge Code: D2157

Total Pages: $-1-G_{\text {ge }} 17$

Key Words: risk management, programmatic risk, tank waste retrieval

Abstract: This Risk Management Plan defines the approach to be taken to manage programmatic risks in the TWRS Tank Waste Retrieval program. It provides specific instructions applicable to TWR, and is used to supplement the guidance given by the TWRS Risk Management procedure.

TRADEMARK DISCLAIMER. Reference herein to any specific commercial product, process, or service by trade name, trademark, manufacturer, or otherwise, does not necessarily constitute or imply its endorsement, recommendation, or favoring by the United States Government or any agency thereof or its contractors or subcontractors.

Printed in the United States of America. To obtain copies of this document, contact: Document Control Services, P.O. Box 950, Mailstop H6-0B, Richland WA 99352, Phone (509) 372-2420; Fax (509) 376-4989.
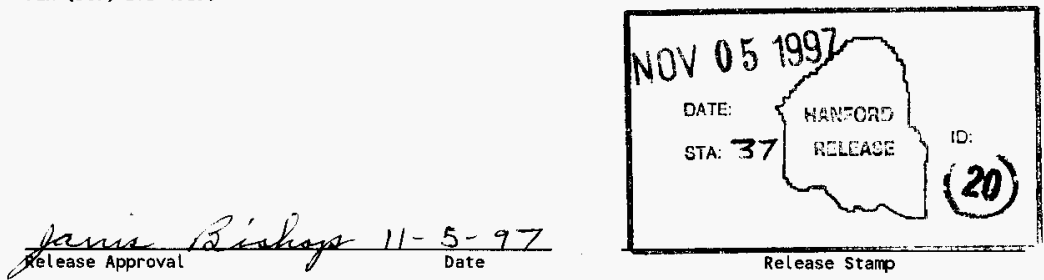

Release Stamp

\section{Approved for Public Release}


HNF-1753

Revision 0

TANK WASTE REMEDIATION SYSTEM

TANK WASTE RETRIEVAL

RISK MANAGEMENT PLAN

Prepared by:

S. C. Klimper

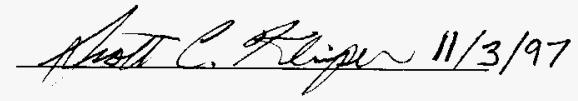

Reviewed by:

B. D. Zimmerman

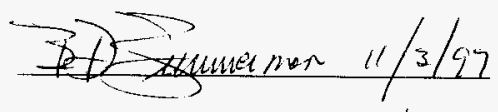

Approved by:

S. M. O'Toole

R. J. Murkowski

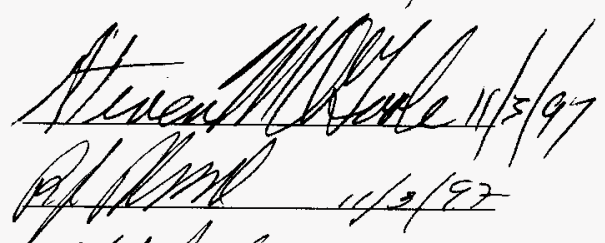

H. L. Boston

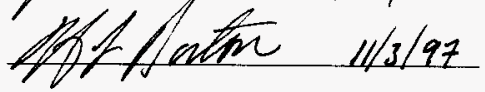


HNF-1753

Revision 0

\section{TANK WASTE REMEDIATION SYSTEM \\ TANK WASTE RETRIEVAL \\ RISK MANAGEMENT PLAN}

\subsection{INTRODUCTION}

\subsection{Purpose}

The purpose of the Tank Waste Remediation System (TWRS) Tank Waste Retrieval (TWR) Risk Management Plan (RMP) is to communicate a consistent approach to risk management that will be used by the TWR organization. This RMP is the TWR implementation plan of the higher-level TWRS RMP, the Systems Engineering Management Plan, and the TWRS Risk Management Procedure. The objectives of TWR's approach to risk management are to:

- Improve probability of success (Finish on cost, on schedule, and product meets intended needs).

- Identify, manage, and/or mitigate liabilities.

- Provide better estimates of schedule and cost as a result of understanding risk.

- Actively manage baseline.

- Communicate status/confidence and show progress.

- Help all levels perform work.

Specific objectives are to:

- Follow the risk management procedure at all levels, starting at the lowest task level $(P-3)$ activities.

- Provide common format and common language.

- Ensure all manager's are trained to the adapted risk management method.

- Ensure method is adopted at the P-3 level and up.

- Evaluate and improve adapted method based on experience.

- Aggressively manage risk handling activities (This means making needed changes in the cost and schedule baselines).

- Promote communication and understanding of liabilities related to risk through documentation and tracking.

The scope of this plan emphasizes the application of risk management methods to Phase I work and systems definition for Phase II and Closure. 
HNF-1753

Revision 0

\subsection{Management Organization and Responsibilities}

This section of the plan describes the organizational structure and staff responsibilities for the TWRS Tank Waste Retrieval programmatic risk management program.

\subsubsection{TWRS Tank Waste Retrieval Director}

The TWRS Tank Waste Retrieval Director is the lead manager for the TWRS Tank Waste Retrieval risk management program. The Director is responsible for overall management and execution of the TWRS Tank Waste Retrieval risk management program. This will include assigning risk management point-ofcontact (POC) responsibilities to a TWR staff member who will assist management in the conduct of the risk management program and be responsible for controlling the overall TWR Risk Management List. The TWR Director will determine which risks require elevation to RL-WDD, the LMHC President, or FDH.

\subsubsection{TWRS Tank Waste Retrieval Managers}

A11 TWRS Tank Waste Retrieval managers, from Task Level Activity Manager level up to the Program Element Manager level are responsible for working with the Director, their manager, and/or the POC on a regular basis to ensure that:

- If appropriate, based on level of management and scope of activities, a designee is assigned POC responsibilities for their organization.

- Task Level Activity Managers identify risk items affecting their activities starting at the lowest level of the WBS structure, and elevate those risk items outside their span of authority to mitigate or control.

- Cost Account/Project Managers assess interfaces, integrate risk activities, direct and coordinate task level risk identification work, and elevate those risk items outside their span of authority to mitigate or control.

- Program Element Managers work across activities and interfaces for their area, integrate and actively support the risk program, and assess risk items for elevation.

- The process (see section 2.0) is executed and documented at the task level.

- Managers assess risks at their level and any risks outside the managers span of authority to mitigate or control are elevated to the next level of management.

- Risk management is a part of day-to-day decision making.

- RMLs are reviewed as needed (Their's and sometimes other's).

- Risk handling actions are prioritized. 


\subsubsection{Risk Management POC (Optiona1)}

A TWRS Tank Waste Retrieval staff member will be the primary POC for TWRS Tank Waste Retrieval risk management activities. The POC is responsible for working with the TWRS Tank Waste Retrieval Director and management to assess, analyze, and handle risks associated with TWRS Tank Waste Retrieval activities. This includes:

- Interfacing with management and key personnel to identify and status risks associated with their activities.

- Working with TWR Business Operations on the integration and implementation of risk activities.

- Guiding management and key personnel in risk management methodology.

- Supporting the establishment and maintenance of a risk database.

- Making recommendations to management to ensure informed risk decisions are made.

- Preparing and distributing risk status reports.

- External coordination of risks affecting other TWRS organizations and system functions.

- Integration of external risks having an impact on the POC's organization and system functions.

- Providing risk management expertise to guide, support, and expedite risk management activities.

- Representing management at risk management working group meetings.

- Maintaining a RM plan that describes how the RM program will be implemented within TWRS Tank Waste Retrieval.

- Provide roll-up of TWR risk items to TWRS SE for incorporation into the overa11 TWRS Risk Management List. 
HNF-1753

Revision 0

\subsection{IMPLEMENTATION}

\subsection{Process Application}

TWR is implementing WHC-IP-0842, Volume IV, Engineering, Section 2.6, Rev. 0a, "Risk Management" procedure. This procedure includes guidelines for how risks will be assessed, analyzed, handled, and archived.

These guidel ines are summarized in Figure 1 and Table 1 as adapted by Tank Waste Retrieval.

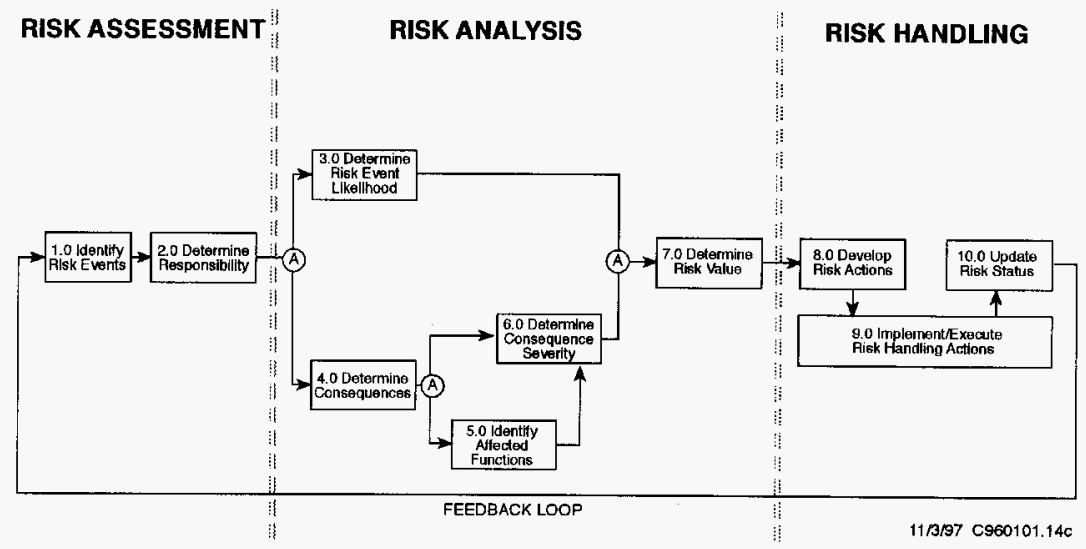

Figure 1 - Risk Management Process 
HNF-1753

Revision 0

Risk Management Process Descriptions

\begin{tabular}{|c|c|c|}
\hline Step & Process & Descrlphion \\
\hline 1.0 & Identify Risk Events & $\begin{array}{l}\text { Starting from the task level (bottom-up approach) } \\
\text { ident ify what potential events pose a risk and generate } \\
\text { a list of risk events. }\end{array}$ \\
\hline 2.0 & Determine Responsibility & $\begin{array}{l}\text { Identify by name the RL POC, the PHMC Responsible } \\
\text { Manager, the PHMC Responsible Contact, and if } \\
\text { applicable the Monitor Contact for the risk event. }\end{array}$ \\
\hline 3.0 & Determine Risk Event Likel ihood & $\begin{array}{l}\text { Assign a rating of Low, Medium, or High based on the } \\
\text { probability of the risk event occurring. }\end{array}$ \\
\hline 4.0 & Determine Consequences & $\begin{array}{l}\text { Prepare a list of consequences if the risk event does } \\
\text { occur. }\end{array}$ \\
\hline 5.0 & Ident ify Affected Functions & $\begin{array}{l}\text { Prepare a list of system functions that are affected by } \\
\text { the risk event and its consequences. This includes } \\
\text { documenting any program logic blocks (Level } 0 \text { and Mid- } \\
\text { level logic) whose cost, schedule, or performance is } \\
\text { affected. }\end{array}$ \\
\hline 6.0 & Determine Consequence Severity & $\begin{array}{l}\text { Assign a rating of Low, Medium, or High based on how } \\
\text { negative the effect will be if a risk event occurs. }\end{array}$ \\
\hline 7.0 & Determine Risk Value & $\begin{array}{l}\text { Using the risk value matrix provided in the procedure, } \\
\text { find the qualitative rating located at the intersection } \\
\text { between risk likelihood and consequence severity. }\end{array}$ \\
\hline 8.0 & Develop Risk Actions & $\begin{array}{l}\text { Prepare a list of risk handling actions that might be } \\
\text { taken to Avoid, Transfer, Share, Control, or Assume the } \\
\text { risk. Identify the current status of each act ion as } \\
\text { Pending, Ongoing, or Complete. I dentify a lead person } \\
\text { for each action. When appropriate, an action plan can } \\
\text { be prepared to ensure the completion of each action. }\end{array}$ \\
\hline 9.0 & $\begin{array}{l}\text { IMPLEMENT/EXECUTE RISK HANDLING } \\
\text { ACTIONS }\end{array}$ & $\begin{array}{l}\text { Develop work scope, cost, schedule, priority, and } \\
\text { basel ine change control products necessary to } \\
\text { implement, execute, and evaluate work. }\end{array}$ \\
\hline 10.0 & Update Risk Status & $\begin{array}{l}\text { Periodically review the status of the risk and handling } \\
\text { actions, and update alt sources of information } \\
\text { accordingly. }\end{array}$ \\
\hline
\end{tabular}

Table 1

Detailed guidance on these steps are available in the referenced Risk Management procedure. Appendix $A$ also contains additional guidance and usefur tools for the risk identification process.

\section{Additional clarification and reminders:}

- TWR will develop RMLs using a bottom-up roll-up approach based on the highligted areas of the WBS in Appendix B.

- Everyone accountable for a task will examine their work scope and document risks using the format of Figure $A 1$ in Appendix $A$. The identified risks will be rolled-up into RMLs starting at WBS Level 6.

- Any risk outside of a managers span of authority to mitigate or control 
will be elevated to the next level. Reasons to consider elevation of risks include:

- Cost increases greater than 10\%

-Critical path slippage

-Risk of impact to other activities/projects/program elements

-Significant chance of missing Performance Agreement

-Potential technical failure

- The responsible managers will define the appropriate RML review and update cycle for their lists dependent on potential event timing and hand 1 ing action urgency.

- The responsible managers will ensure that any TWR risks resulting from external factors or other organization's work (e.g., Operations, Safety, Characterization) are captured in their RMLs. Note: Assumptions made in the program logic decomposition process should also be assessed for any potential risk events they may generate.

- A11 RML entries will include information on which mid-level logic blocks are affected by the potential risk event and this information will be placed in an appropriate database field to allow database sorts by program logic block. 
HNF -1753

Revision 0

\subsection{IMPLEMENTATION SCHEDULE}

- Implement Risk Management training - 10/29/97 (COMPLETE)

- Produce initial risk 1ists per WBS - 11/14/97

- Create initial RML databases - 12/05/97

- Evaluate RMP for necessary changes based on experience - 1/30/98

- Issue updated RMP - 3/06/98

\subsection{REFERENCES}

WHC-SD-WM-SEMP-002, Revision 0, "Tank Waste Remediation System Systems Engineering Management Plan, dated February 5, 1996.

WHC-SD-WM-PMP-018, Revision 1, "Tank Waste Remediation System Risk Management Plan, "' July 1996.

WHC-IP-0842, Volume IV, Engineering, Section 2.6, Rev. 0a, "Risk Management ${ }^{H \prime}$ procedure, dated September 30, 1996. 
HNF-1753

Revision 0

\section{APPENDIX A}

\section{SYSTEMATIC RISK REVIEW PROCESS}


HNF-1753

Revision 0

\section{Systematic Risk Review Guideline}

A systematic review process is needed to identify where risk events may occur in a project. To discover these risk events, project and task managers systematically describe the tasks required for the project. Then they analyze the tasks for points where there is a possibility of failure. Identifying these points is the first step in managing risk.

Each level of responsibility reviews tasks at their level and follows the process step by step, focusing on critical points that could cause failure. Potential risk areas include cost, schedule, performance (technical \& quality) and product acceptance (clearly communicating for acceptance). External influences that could impact the task are reviewed. These influences can come from outside the overall project, from another task or from another level within the project. They include assumptions the project is operating under, and the ability to communicate to gain acceptance for the work. In addition, ancillary activities which could impact the task process need to be identified (e.g. administrative support, work procedures or resources could have a significant influence on the project results).

The following can be used to help guide this review.

What tasks are you responsile for?

(Look at the logic and P-3 schedule tasks you are responsible for) 
For each task listed ask the following questions and place the answers in the appropriate column of Figure Al (It is recommended that a table with the format of Figure $A 1$ be created in Microsoft Excel, and used to document the derived risk information):

What can go wrong?

Potential risk areas to consider include:

- Cost

- Schedule

- Performance (Technical)

- Performance (Quality)

- Product Acceptance

- Communication

- External Influences

- Ancillary Activities (administrative support, work procedures or resources)

- Assumptions

What are the risk events?

What are the probability and consequences of the event?

Complete Figure $\mathrm{A} 1$ by documenting appropriate risk handling actions, and assessing which risk events may require elevation to the next level. 


\section{Glossary for Figure Al Fields}

Task Description, WBS \#:

A short description of the evaluated task and what WBS number it falls under. The names of the PHMC Responsible Manager and the RL POC should be included.

Risk Event(s) Description:

Description of the potential risk event, including what WBS elements may be affected and what mid-level logic blocks may be impacted.

Probability $(L, M, H)$ :

The probability (likelihood) that the risk event may happen. This should be a value of Low, Medium, or High. Refer to the Risk Management Procedure if additional guidance is required.

Consequence(s) (Technical, Schedule, Cost):

Description of the consequences if the risk event happens. General, high-level quantification of the consequences should be included.

Consequence $(L, M, H)$ :

The severity of the consequences if the risk event occurs. This should be a value of Low, Medium, or High and is based on the identifier's judgement.

Risk Value (Probability $x$ Consequence):

A value of Very Low, Low, Medium, High, or Very High based on the risk value matrix. (See the Risk Management Procedure)

Risk Handling Options (Avoid, Transfer, Control, Accept) :

A description of the risk handling actions, and if possible what type they are, chosen to manage the liabilities associated with the risk event.

Handling Actions (Due dates):

Date by which the handling actions must be completed. One can also add interim review dates for the actions.

Status $(P, 0, C)$ :

This is the status of each individual handling action. They can be classified as pending (not yet started), ongoing, or complete.

Point of Contact:

This is the "owner" of the potential risk event, also called the PHMC Responsible Contact.

Risk Status (R, A, G):

This is the PHMC Responsible Contact's perception of how well the risk handling actions are going, and how well the actions will mitigate the liabilities. The values are Red (handling actions expected to fall far short of reducing risk to an acceptable level, "inadequate"), Amber (may fal1 short, "marginal"), Green (expected to reduce risk to an acceptable level, "adequate").

Lead Person:

This is the individual responsible for an individual handling action. 


\begin{tabular}{|l|l|l|l|l|l|}
\hline $\begin{array}{l}\text { Task } \\
\text { Description } \\
\text { WBS\# }\end{array}$ & $\begin{array}{l}\text { Risk Event(s) } \\
\text { Description }\end{array}$ & $\begin{array}{l}\text { Probabiitity } \\
\text { L,M.H }\end{array}$ & $\begin{array}{l}\text { Conf } \\
\text { Tec } \\
\text { Scr }\end{array}$ & $\begin{array}{l}\text { Risk Status } \\
\text { R.A.G }\end{array}$ & $\begin{array}{l}\text { Lead } \\
\text { Person }\end{array}$ \\
\hline
\end{tabular}




\section{APPENDIX B}

\section{RISK MANAGEMENT LISTS \\ AND \\ ROLL-UP PROCESS \\ BASED ON WBS}


HNF-1753

Revision 0

APPENDIX B

The following table lists by WBS number the organizations that will maintain risk management lists. Responsible persons are also listed. Roll-up of risk items will follow the WBS structure (and is indicated by indenting in the table below).

ORG. NAME

WBS NUMBER

CONTACT

\begin{tabular}{|c|c|c|}
\hline TWRS Waste Disposal & 1.1 .1 .3 & H. Boston \\
\hline Waste Feed Delivery & 1.1 .1 .3 .01 .01 & R. Powel1 \\
\hline Project Mgt/Admin & 1.1 .1 .3 .01 .01 .01 & R. Powel1 \\
\hline $\begin{array}{l}\text { Feed Process Systems } \\
\text { Def. }\end{array}$ & 1.1 .1 .3 .01 .01 .02 & J. Garfield \\
\hline Retrieval Systems Def. & 1.1 .1 .3 .01 .01 .03 & R. Marshal1 \\
\hline Project $W-151$ & 1.1 .1 .3 .01 .01 .04 & E. Nordquist \\
\hline Project $W-211$ & 1.1 .1 .3 .01 .01 .05 & J. VanBeek \\
\hline $\begin{array}{l}\text { Project } W-320 \\
\text { (incl. } W-030)\end{array}$ & 1.1 .1 .3 .01 .01 .06 & J. Lentsch \\
\hline ISSTRS & 1.1 .1 .3 .01 .01 .07 & R. Marshall \\
\hline SSSTRS & 1.1 .1 .3 .01 .01 .08 & R. Marshall \\
\hline Phase I Retrieval 0ps & 1.1 .1 .3 .01 .01 .09 & F. Jensen \\
\hline $\begin{array}{l}\text { Future DST Retrieval } \\
\text { Projects }\end{array}$ & 1.1 .1 .3 .01 .01 .10 & R. Marshall \\
\hline Project $W-314$ & 1.1 .1 .3 .01 .01 .12 & W. Rutherford \\
\hline SST and DST Closure & 1.1 .1 .3 .01 .02 & E. Fredenberg \\
\hline Process Waste Support & 1.1 .1 .3 .05 .01 & P. Kerns \\
\hline Phase I Infrastructure & 1.1 .1 .3 .08 .01 & B. Root \\
\hline $\begin{array}{l}\text { Immobilized Tank Waste } \\
\text { Storage \& Disposal }\end{array}$ & 1.1 .1 .3 .04 & R. Murkowski \\
\hline ILAW Storage / Disposal & 1.1 .1 .3 .04 .01 & J. Voogd \\
\hline Systems Definition & 1.1 .1 .3 .04 .01 .02 & C. Peterson \\
\hline Project $W-465$ & 1.1 .1 .3 .04 .01 .04 & K. Burgard \\
\hline Operations & 1.1 .1 .3 .04 .01 .05 & J. Voogd \\
\hline
\end{tabular}


HNF-1753

Revision 0

\begin{tabular}{|l|l|l|}
\hline IHLW Storage & $1.1 \cdot 1.3 .04 .02$ & J. Voogd \\
\hline System Definition & 1.1 .1 .3 .04 .02 .02 & C. Peterson \\
\hline Project W-464 & 1.1 .1 .3 .04 .02 .03 & K. Burgard \\
\hline Operations & 1.1 .1 .3 .04 .02 .04 & K. Burgard \\
\hline
\end{tabular}

(Transfer of Project W-314 to TWR is expected before the end of calendar 1997.) 


\section{DISTRIBUTION COVERSHEET}

Author

S. C. Klimper 373-0078
Addressee

EDT No.

Distribution

Document ritle: TWRS Tank Waste Retrieval Risk Management Plan

\section{DISTRIBUTION}

Lockheed Mart in Hanford Corporation

J. F. Bores G3-2l

H. L. Boston

G3-21

D. L. Burt

G3-21

P. A. Craig

K. A. Gasper

G3-21

R. J. Murkowski

H6-37

D. A. Myers

H5- 03

R. W. Powe11

G3-21

S. M. O'Toole

H5-03

R. W. Root

G3-21

W. T. Thompson

H6- 12

G3-21

R. L. Treat

J. A. Voogd

H5- 03

H5-03

R. D. Wojtasek

G3-21

R. F. Wood

H5- 03

B. D. Zimmerman

H6-35

$x$

$x$
$x$

Numatec Hanford Corporation

J. N. Alibert

E. A. Fredenburg

J. S. Garfield

S. C. Klimper

R. P. Marshall

Central Files
S2-48

H6-12

H5- 49

H6-35

H5-61

B] -07

$x$ 